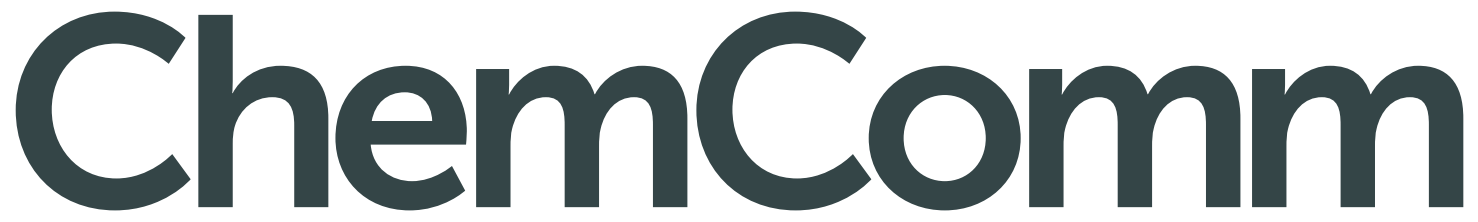

Chemical Communications

www.rsc.org/chemcomm
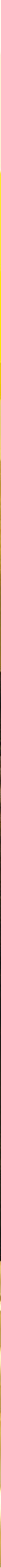

ISSN 1359-7345

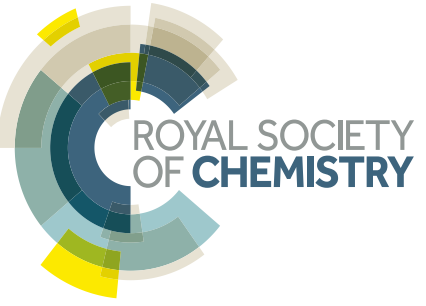

COMMUNICATION

Karl-Heinz Ernst et al.

Surface-assisted diastereoselective Ullmann coupling of bishelicenes

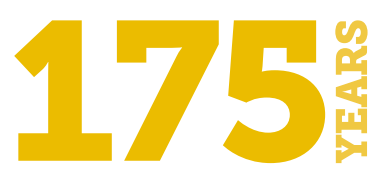




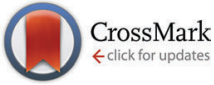

Cite this: Chem. Commun., 2016, 52, 12694

Received 15th July 2016, Accepted 13th September 2016

DOI: $10.1039 / \mathrm{c} 6 \mathrm{cc} 05849 \mathrm{c}$

www.rsc.org/chemcomm

\section{Surface-assisted diastereoselective Ullmann coupling of bishelicenes $\dagger$}

\author{
Christian Wäckerlin, ${ }^{a}$ Jingyi Li, ${ }^{a}$ Anaïs Mairena, ${ }^{a}$ Kévin Martin, ${ }^{\mathrm{b}}$ Narcis Avarvari ${ }^{\mathrm{b}}$ and \\ Karl-Heinz Ernst*ac
}

\begin{abstract}
Ullmann coupling of chiral 2-bromo[4] helicene has been performed on a $\mathrm{Cu}(100)$ surface. Only homochiral 2,2'-bis[4]helicene as the product is observed using STM. Such stereoselectivity is based on the fact that the surface will favour a configuration with the central part of the molecule on the surface, causing the outer ends to spiral away from the surface.
\end{abstract}

Chiral recognition among molecules on surfaces plays an important role in enantioselective catalysis, ${ }^{1}$ biomineralization, ${ }^{2}$ and for the resolution of chiral molecules into pure enantiomers via crystallization $^{3}$ or chromatography. ${ }^{4}$ Molecular helicity, as one manifestation of chirality, ${ }^{5}$ has also important ramifications in molecular biology. ${ }^{6}$ However, the way helical molecules interact with each other and assemble into macroscopic structures is still an open question. In order to better understand such complex intermolecular interactions, surface self-assembly of chiral and helical molecules has attracted much interest recently. ${ }^{7-10}$ Helicenes also show good potential for serving as functional materials in thin film organic electronic devices like light sensors or spin filters. ${ }^{11,12}$ However, strategies for more stable films call for approaches beyond non-covalent self-assembly, like covalent bonding strategies, for example.

In particular, for carbon-carbon coupling of adsorbed molecules the Ullmann reaction ${ }^{13}$ has been very successful. ${ }^{14-34}$ Initially a surface-assisted scission of the carbon-halogen bond occurs and leads to the formation of a carbon-metal-carbon binding motif. Upon annealing at higher temperatures, the metal atoms are released and new carbon-carbon bonds are formed.

The up-down asymmetry of the surface excludes any centre of inversion and is therefore predestined to induce stereochemical

\footnotetext{
${ }^{a}$ Empa, Swiss Federal Laboratories for Materials Science and Technology,

Überlandstrasse 129, 8600 Dübendorf, Switzerland.

E-mail: karl-heinz.ernst@empa.ch

${ }^{b}$ Laboratoire Moltech Anjou, Université d'Angers, Angers, France

${ }^{c}$ Department of Chemistry, University of Zurich, Zurich, Switzerland

$\dagger$ Electronic supplementary information (ESI) available: Large scale scanning tunnelling images, X-ray photoelectron spectra, molecular mechanics and extended Hückel simulations. See DOI: 10.1039/c6cc05849c
}

effects for molecules that differentiate between up and down. Here we demonstrate by means of scanning tunnelling microscopy (STM) and X-ray photoelectron spectroscopy (XPS) that copper surface adatoms C-C-couple two helicenes such that only $(M, M)$ - and $(P, P)$-enantiomers are obtained (Scheme 1). Neither the $(M, P)$-diastereomer nor any syn isomer is observed in longrange ordered two-dimensional (2D) structures (Scheme S1, ESI $\dagger$ ). The synthesized bishelicenes crystallize into a $2 \mathrm{D}$ conglomerate with homochiral domains. In disordered areas, intermediate [4]helicene-Cu-[4]helicene complexes are also identified.

The experiments were performed in ultrahigh vacuum on the (100) surface of a copper single crystal, cleaned by cycles of $\mathrm{Ar}^{+}$ion sputtering and healed by subsequent annealing at 773 K. STM images were recorded in constant current mode using a mechanically cut and in situ $\mathrm{Ar}^{+}$-sputtered PtIr (90\% Pt) tip in a Specs Aarhus 150 instrument. XP spectra were acquired using $\mathrm{Al} \mathrm{K} \alpha \mathrm{X}$-rays. The binding energy scale was calibrated using the $\mathrm{Cu} 2 \mathrm{p}_{3 / 2}$ signal $(932.7 \mathrm{eV})$ and the Fermi edge $(\cong 0.0 \mathrm{eV})$ in survey spectra. After prolonged degassing, 1 was thermally evaporated from a crucible kept at $343 \mathrm{~K}$.

Only at coverages yielding a densely packed monolayer are product molecules sufficiently immobile to be imaged by STM at room temperature (RT). Deposition of roughly $1.5 \mathrm{ML}$ of 1

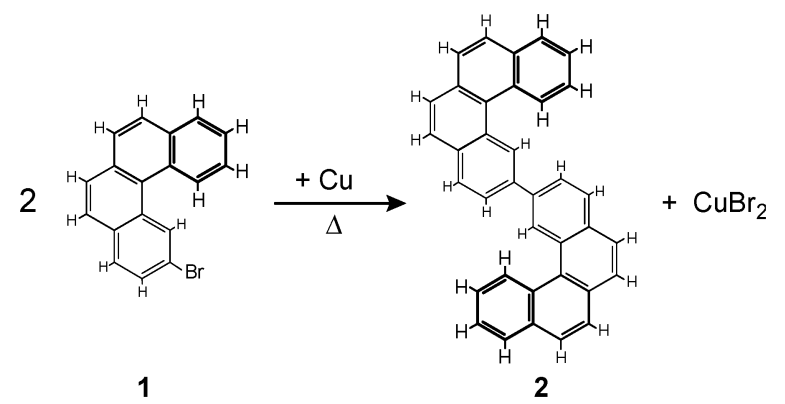

Scheme 1 Ullmann coupling between two 2-bromo[4]helicenes (1) leading to $2,2^{\prime}$-bis[4]helicene (2). The main products formed on the $\mathrm{Cu}(100)$ surface are anti-(P,P)-2 and anti-(M,M)-2. 
onto $\mathrm{Cu}(100)$ and subsequent annealing to $463 \mathrm{~K}$ induce the Ullmann coupling and cause desorption of second layer molecules. Due to their high surface mobility, molecules in lower coverage samples or in samples prior to annealing could not be imaged at temperatures above $130 \mathrm{~K}$.

The scission of the carbon-bromine bond, which is the initial step in the Ullmann reaction, can be followed using the Br 3p XP spectroscopy (Fig. 1). After deposition at $110 \mathrm{~K}$, the $\mathrm{Br} 3 \mathrm{p}_{3 / 2}$ peak maximum is observed at a binding energy of $184.4 \mathrm{eV}$, consistent with intact $\mathrm{C}-\mathrm{Br}$ bonds. ${ }^{24,25}$ Upon dissociation a prominent shift to a lower binding energy is observed. XPS results show that the $\mathrm{C}-\mathrm{Br}$ bond scission occurs partly at $183 \mathrm{~K}$ and is completed already at $228 \mathrm{~K}$. This temperature range is consistent with a previous report on $4,4^{\prime \prime}$-dibromoterphenyl on $\mathrm{Cu}(111)$ $(170 \mathrm{~K}<T<240 \mathrm{~K}) .^{24}$

In accordance with previous results, ${ }^{19,24}$ the sample needs to be annealed to higher temperatures for carbon-carbon coupling. Fig. 2 exhibits STM images recorded after annealing at $463 \mathrm{~K}$. The large-scale image (Fig. 2a) shows self-assembled domains of the bishelicene product appearing as " $S$ " and " $\mathrm{Z}$ ". In a highresolution image (Fig. 2b) the terminal benzo groups of the bishelicenes are clearly resolved due to their higher brightness. In STM, when operated in constant current mode, parts of a

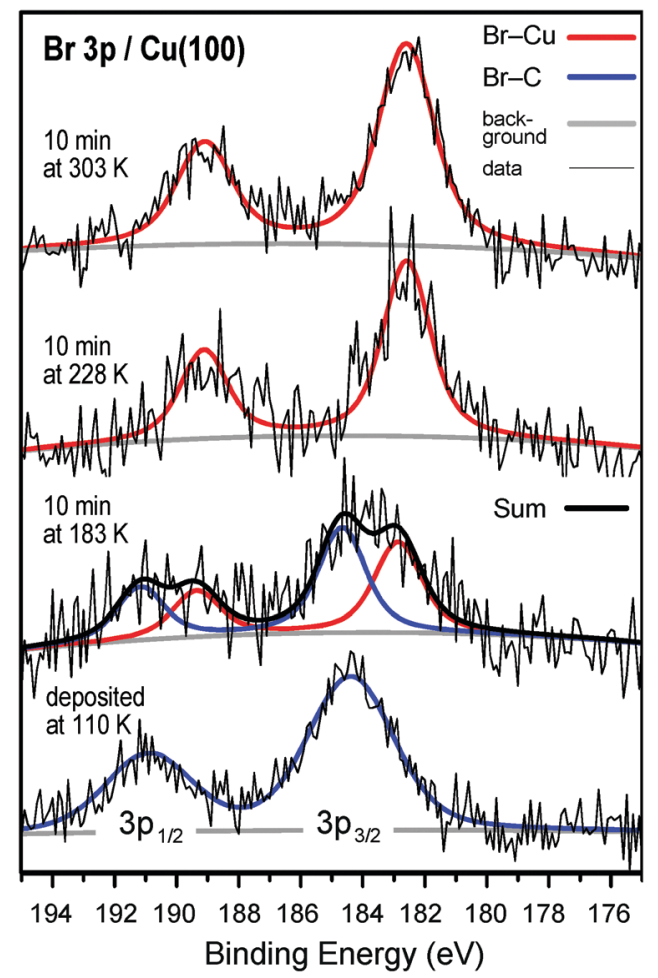

Fig. 1 Series of XP spectra of the $\mathrm{Br} 3 p$ region after deposition of 1 on $\mathrm{Cu}(100)$, kept at $110 \mathrm{~K}$, and subsequent annealing. The background, as obtained from the clean sample, has been subtracted. The $3 p$ electron binding energies are characteristic of the chemical state of the bromine atom. When bromine is still connected to a carbon atom of the helicene it has its $3 p_{3 / 2}$ peak maximum at $184.4 \mathrm{eV}$ binding energy (blue curves), but shifts by $1.6 \mathrm{eV}$ to lower energy when disconnected and bound to surface copper atoms (red curves).
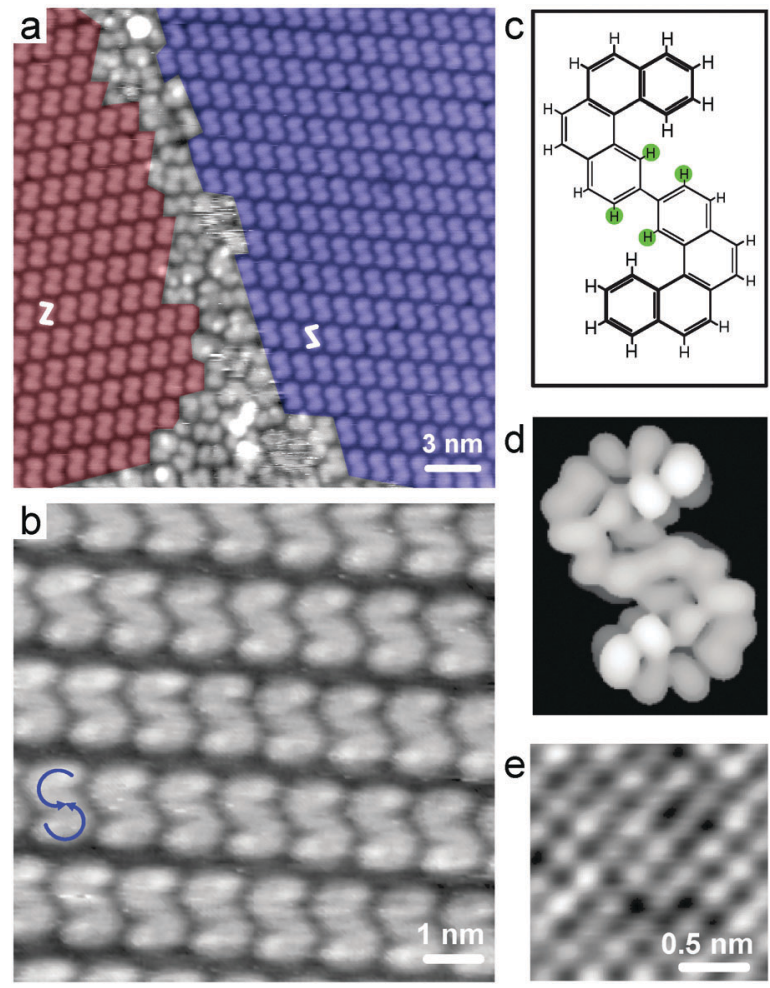

Fig. 2 STM images obtained after sublimation of 1 on $\mathrm{Cu}(100)$ and annealing to $463 \mathrm{~K}$. (a) Large scale image $(U=1.2 \mathrm{~V}, I=30 \mathrm{pA}, T=295 \mathrm{~K})$ revealing self-assembled domains of $(P, P)-\mathbf{2}$ (red) and $(M, M)-\mathbf{2}$ (blue). (b) STM image $(U=1.8 \mathrm{~V}, I=30 \mathrm{pA}, T=295 \mathrm{~K})$ of a domain of $(M, M)-2$ exhibiting intramolecular resolution. The blue circular arrows indicate the handedness of the helices: going counterclockwise from bright to darker (up-to-down) identifies the $M$-helix. (c) Molecular structure of $(M, M)-2$ with 'biphenyl'hydrogens highlighted in green and (d) electron density of the lowest 3 unoccupied molecular orbitals calculated using extended Hückel theory (see text). (e) Atomic resolution for bare $\mathrm{Cu}(100)(U=4 \mathrm{mV}, I=600 \mathrm{pA}$, $T=300 \mathrm{~K})$

molecule farther away from the surface are coded with relatively larger brightness. Hence, both ends of the bishelicene turn from high to low in a counterclockwise rotation (blue arrows in Fig. 2b), which leads unambiguously to the conclusion that the product with the " $\mathrm{S}$ " appearance is a $(M, M)$-isomer. Accordingly, the entity appearing as " $\mathrm{Z}$ " is $(P, P)$-2. This also implies that the inner lower part of the bishelicene is adsorbed close to the surface. The steric repulsion between the $\mathrm{H}$-atoms located in the ortho-position to the connecting bond in this biphenyl motif (see green solid circles in Fig. 2c) does not cause a twist, because it is overruled by significant $\pi$-metal interactions. This conclusion is consistent with the planar adsorption geometry of $p$-hexaphenyl on $\mathrm{Au}(111) .{ }^{35}$ Note that the unoccupied frontier orbitals simulated using extended Hückel theory after geometry optimization of $(M, M)$-2 on a single $\mathrm{Cu}(100)$ layer (Fig. 2d) agree very well with the observed STM contrast, thereby confirming the assignment of the sense of helicity of the two helical subunits. The two bis[4]helicene enantiomers self-assemble into homochiral 2D conglomerates. Due to the fourfold symmetry of the $\mathrm{Cu}(100)$ substrate, four rotational domains coexist for each mirror domain. 
Without any stereoselective influence during the Ullmann reaction of bromo[4] helicene and the following self-assembly, a $2: 1: 1$ ratio is expected for the products $(P, M)-2:(P, P)-2$ : $(M, M)-2$, respectively. However, we did not observe $(P, M)-2$ isomers at all. In such a case one helix would 'spiral' towards - and the other away - from the surface. The regular Ullmann coupling is performed over Cu-powder, ${ }^{13}$ so stereoselectivity could be observed there as well. However, at the required high temperature of $\approx 473 \mathrm{~K}$, the low barrier for the inversion of the biphenyl part $\left(2 \mathrm{kcal} \mathrm{mol}^{-1}\right)^{36,37}$ and the helix inversion $\left(\approx 4 \mathrm{kcal} \mathrm{mol}^{-1}\right.$, Table S1, ESI $\dagger$ ) will yield all diastereomers and conformational isomers as well.

Because $\mathrm{Cu}$ adatoms act directly at the surface, the bromine part needs to be close to the surface in order to support the Ullmann reaction. When the two helicenes couple through a $\mathrm{Cu}$ surface adatom, their opposite ends will spiral upwards, leading to homochiral bishelicenes. Due to the relatively low inversion barrier of about $4 \mathrm{kcal} \mathrm{mol}^{-1}$, the [4] helicenes will easily adopt such a favoured conformation under reaction conditions. However, at such a high temperature all other isomers will then form after the reaction due to the low inversion barriers. We conclude therefore that the observed diastereoselectivity has originated in a post-reaction step. Upon cooling all isomers will be switched to the $(P, P)$ and $(M, M)$ configurations, because the interaction with the surface is maximized with the middle bisphenyl part being located close to the surface. Moreover, this arrangement disfavours the $\operatorname{syn}-(M, P)$ configuration due to steric overcrowding at the upper ends.

Roughly $60 \%$ of the surface is usually covered with ordered arrays of product, whilst a disordered layer of different molecules accounts for the rest of the surface (Fig. 3). Not all molecules in the disordered domains can be identified, but a significant fraction appears as $(P, P)-2$ and $(M, M)$-2. However, longer species

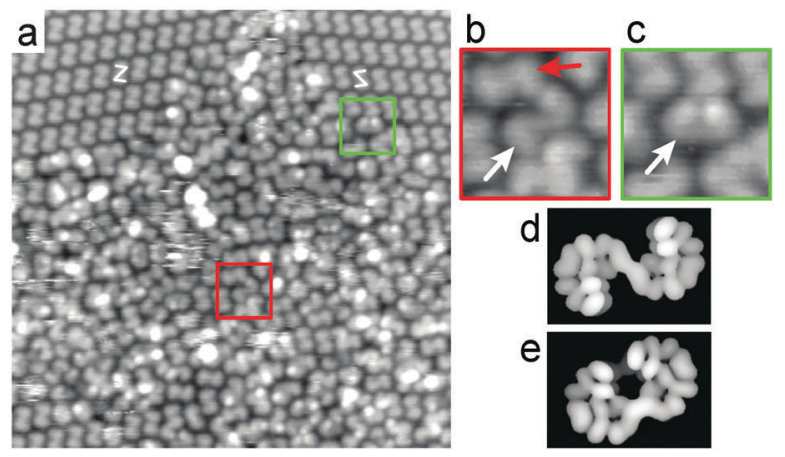

Fig. 3 (a) STM image $\left(30 \times 30 \mathrm{~nm}^{2}, U=1.2 \mathrm{~V}, I=30 \mathrm{pA}, T=295 \mathrm{~K}\right)$ of a disordered area near ordered domains. A 'longer' anti-species (b, white arrow) and a syn-species (c, white arrow) are frequently observed in the disordered layer in addition to anti-2 (b, red arrow). The ends of the longer anti- (b) and the syn-species (c) appear significantly farther apart than those of the regular anti-2. Therefore, with the help of molecular mechanics simulations performed for all species under consideration (Table S1, ESI $\dagger$ ), the longer anti- and syn-species are identified as $\mathrm{C}-\mathrm{Cu}-\mathrm{C}$ intermediates. ${ }^{26,33}$ Electron density of the lowest 3 unoccupied molecular orbitals calculated using extended Hückel theory for the organometallic anti- $(P, P)(\mathrm{d})$ and syn- $(M, P)(\mathrm{e})$ intermediates. are also observed. All three species differ in their apparent length at half height intensity, as determined from Fig. 3 and from images recorded under identical imaging conditions and without any tip-change. + We find an apparent length of $14.6 \pm 0.4 \AA$ for 2 , $17.0 \pm 0.3 \AA$ for the longer product (Fig. 3b) and 16.2 $\pm 0.4 \AA$ for the syn-product (Fig. 3c). In order to make a good assignment of these two species we compared these values with the lengths of simulated anti- and syn-bishelicenes both as organic (i.e. compound 2) and organometallic $(\mathrm{C}-\mathrm{Cu}-\mathrm{C})$ intermediate species (Table S2, ESI $\dagger$ ). The difference in apparent length of the regular anti-2 and the long anti-bishelicenes agrees well with the elongation of the bishelicenes due to the presence of $\mathrm{Cu}$ in the long anti species. The observed syn-species is longer than the regular anti-2, but the simulated syn-2 is shorter than the simulated anti-2 species. This excludes the fact that the observed $s y n$-bishelicenes correspond to syn-2. Hence, we conclude that the long anti-bishelicenes and the syn-bishelicenes are organometallic intermediates.

We also studied the Ullmann reaction on an oxygen reconstructed $\mathrm{Cu}(100)$ surface. ${ }^{38}$ Compared to bare $\mathrm{Cu}(100)$, a much higher temperature for $\mathrm{C}-\mathrm{Br}$ bond scission (338 K, Fig. S2, ESI $\dagger$ ) is required for $\mathrm{O} / \mathrm{Cu}(100)$, consistent with the observation of intact $\mathrm{C}-\mathrm{Br}$ bonds of aryl bromides on other $\mathrm{O} / \mathrm{Cu}$ surfaces at room temperature. ${ }^{33,39}$ After annealing to $463 \mathrm{~K}$ no long-range ordered self-assembled domains, but single bishelicenes in anti- and syn-conformation are observed (Fig. S3, ESI $\dagger$ ). From the apparent lengths of the anti- and syn-bishelicenes on $\mathrm{O} / \mathrm{Cu}(100)$ (16.5 $\pm 0.6 \AA$ and $15.5 \pm 0.5 \AA$, respectively) we identify both as organometallic intermediates. These observations for $\mathrm{O} / \mathrm{Cu}(100)$ are consistent with previous results that the Ullmann coupling in solution proceeds better on metallic than on oxidized $\mathrm{Cu}$ particles. ${ }^{14,40}$

In conclusion, the Ullmann coupling between 2-bromo[4]helicenes yields only the homochiral combinations of $(P, P)-2$ and $(M, M)-2$ on the $\mathrm{Cu}(100)$ surface, in which their ends spiral upwards away from the surface with the $\mathrm{C}$-C-coupled middle part close to the surface. The enantiomers resolve laterally into 2D conglomerates of homochiral domains. $(P, M)$-2 diastereomers are not observed. How much the low inversion barrier of [4] helicene contributes to the diastereomeric coupling between helicenes will be evaluated by studying the Ullmann coupling with helicenes with higher barriers for helix-inversion, e.g. 2-bromoheptahelicene. New insight into mechanisms of covalent linking is important for the development of stereoselective processes to highly functional materials and catalysts.

Financial support from the Schweizerischer Nationalfonds and the University Zurich priority program LightChEC is gratefully acknowledged.

\section{Notes and references}

$\ddagger$ The STM was calibrated on the atomically resolved $\mathrm{Cu}(100)$ surface. The confidence in absolute lengths is $\pm 3 \%$.

1 H.-U. Blaser, Tetrahedron: Asymmetry, 1991, 2, 843-866.

2 L. Addadi and S. Weiner, Nature, 2001, 411, 753-755.

3 L. Pérez-García and D. B. Amabilino, Chem. Soc. Rev., 2007, 36, 941-967. 
4 Chiral recognition in separation methods: mechanisms and applications, ed. A. Berthod, Springer, Heidelberg, 2010.

5 R. S. Cahn, C. Ingold and V. Prelog, Angew. Chem., Int. Ed. Engl., 1966, 5, 385-415.

6 T. Nakano and Y. Okamoto, Chem. Rev., 2001, 101, 4013-4038.

7 K.-H. Ernst, Phys. Status Solidi B, 2012, 249, 2057-2088.

8 R. Raval, in Chirality at the Nanoscale, ed. D. B. Amabilino, Wiley-VCH, Weinheim, 2009.

9 K.-H. Ernst, Acc. Chem. Res., 2016, 49, 1182-1190.

10 M. Gingras, Chem. Soc. Rev., 2013, 42, 1051-1095.

11 Y. Yang, R. C. da Costa, M. J. Fuchter and A. J. Campbell, Nat. Photonics, 2013, 7, 634-638.

12 V. Kiran, S. P. Mathew, S. R. Cohen, I. Hernández Delgado, J. Lacour and R. Naaman, Adv. Mater., 2016, 28, 1957-1962.

13 F. Ullmann and J. Bielecki, Ber. Dtsch. Chem. Ges., 1901, 34, 2174-2185.

14 M. Xi and B. E. Bent, J. Am. Chem. Soc., 1993, 115, 7426-7433.

15 L. Grill, M. Dyer, L. Lafferentz, M. Persson, M. V. Peters and S. Hecht, Nat. Nanotechnol., 2007, 2, 687-691.

16 M. Bieri, M. Treier, J. Cai, K. Aït-Mansour, P. Ruffieux, O. Gröning, P. Gröning, M. Kastler, R. Rieger, X. Feng, K. Müllen and R. Fasel, Chem. Commun., 2009, 6919.

17 J. A. Lipton-Duffin, O. Ivasenko, D. F. Perepichka and F. Rosei, Small, 2009, 5, 592-597.

18 J. A. Lipton-Duffin, J. A. Miwa, M. Kondratenko, F. Cicoira, B. G. Sumpter, V. Meunier, D. F. Perepichka and F. Rosei, Proc. Natl. Acad. Sci. U. S. A., 2010, 107, 11200-11204.

19 J. Cai, P. Ruffieux, R. Jaafar, M. Bieri, T. Braun, S. Blankenburg, M. Muoth, A. P. Seitsonen, M. Saleh, X. Feng, K. Müllen and R. Fasel, Nature, 2010, 466, 470-473.

20 M.-T. Nguyen, C. A. Pignedoli and D. Passerone, Phys. Chem. Chem. Phys., 2011, 13, 154-160.

21 L. Lafferentz, V. Eberhardt, C. Dri, C. Africh, G. Comelli, F. Esch, S. Hecht and L. Grill, Nat. Chem., 2012, 4, 215-220.

22 L. Cardenas, R. Gutzler, J. Lipton-Duffin, C. Fu, J. L. Brusso, L. E. Dinca, M. Vondráček, Y. Fagot-Revurat, D. Malterre, F. Rosei and D. F. Perepichka, Chem. Sci., 2013, 4, 3263.
23 Q. Fan, C. Wang, Y. Han, J. Zhu, W. Hieringer, J. Kuttner, G. Hilt and J. M. Gottfried, Angew. Chem., Int. Ed., 2013, 52, 4668-4672.

24 M. Chen, J. Xiao, H.-P. Steinrück, S. Wang, W. Wang, N. Lin, W. Hieringer and J. M. Gottfried, J. Phys. Chem. C, 2014, 118, 6820-6830.

25 J. Eichhorn, T. Strunskus, A. Rastgoo-Lahrood, D. Samanta, M. Schmittel and M. Lackinger, Chem. Commun., 2014, 50, 7680.

26 Q. Fan, C. Wang, L. Liu, Y. Han, J. Zhao, J. Zhu, J. Kuttner, G. Hilt and J. M. Gottfried, J. Phys. Chem. C, 2014, 118, 13018-13025.

27 T. Dienel, J. Gómez-Díaz, A. P. Seitsonen, R. Widmer, M. Iannuzzi, K. Radican, H. Sachdev, K. Müllen, J. Hutter and O. Gröning, ACS Nano, 2014, 8, 6571-6579.

28 R. Gutzler, L. Cardenas, J. Lipton-Duffin, M. El Garah, L. E. Dinca, C. E. Szakacs, C. Fu, M. Gallagher, M. Vondráček, M. Rybachuk, D. F. Perepichka and F. Rosei, Nanoscale, 2014, 6, 2660.

29 L. Dong, P. N. Liu and N. Lin, Acc. Chem. Res., 2015, 48, 2765-2774.

30 Q. Fan, J. M. Gottfried and J. Zhu, Acc. Chem. Res., 2015, 48, 2484-2494.

31 Q. Fan, T. Wang, L. Liu, J. Zhao, J. Zhu and J. M. Gottfried, J. Chem. Phys., 2015, 142, 101906.

32 T. Anh Pham, F. Song, M.-T. Nguyen, Z. Li, F. Studener and M. Stöhr, Chem. - Eur. J., 2016, 22, 5937-5944.

33 Q. Fan, J. Dai, T. Wang, J. Kuttner, G. Hilt, J. M. Gottfried and J. Zhu, ACS Nano, 2016, 10, 3747-3754.

34 P. Ruffieux, S. Wang, B. Yang, C. Sánchez-Sánchez, J. Liu, T. Dienel, L. Talirz, P. Shinde, C. A. Pignedoli, D. Passerone, T. Dumslaff, X. Feng, K. Müllen and R. Fasel, Nature, 2016, 531, 489-492.

35 S. Müllegger, K. Hänel, T. Strunskus, C. Wöll and A. Winkler, ChemPhysChem, 2006, 7, 2552-2558.

36 K. Müllen, W. Heinz, F. G. Klärner and W. R. Roth, Chem. Ber., 1990, 123, 2349-2371.

37 L. A. Carreira and T. G. Towns, J. Mol. Struct., 1977, 41, 1-9.

38 F. Jensen, F. Besenbacher, E. Laegsgaard and I. Stensgaard, Phys. Rev. B: Condens. Matter Mater. Phys., 1990, 42, 9206-9209.

39 M. El Garah, J. Lipton-Duffin, J. M. MacLeod, R. Gutzler, F. Palmino, V. Luzet, F. Chérioux and F. Rosei, Chem. - Asian J., 2013, 8, 1813-1817.

40 K. S. Suslick, D. J. Casadonte and S. J. Doktycz, Chem. Mater., 1989, 1, 6-8. 